

\section{Artigo Especial}

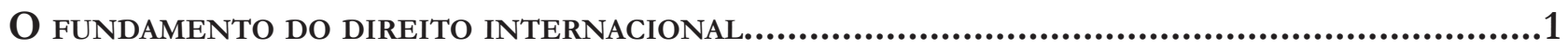
Alfred Verdross

\section{Proteção Internacional dos Direitos Humanos}

INDIGENOUS RIGHTS MOVEMENT: IS THE SAME NEEDED TO PREVENT CONTINUED HUMAN RIGHTS VIOLATIONS OF THE MENTALLY ILL

Liesel LeCates

O Discurso DAS DROGAS CONSTRUído PELO DIREITO INTERNACIONAL

Camila Soares Lippi

O ESTADO DEMOCRÁTICO DE DIREITO LAICO E A "NEUTRALIDADE" ANTE A INTOLERÂNCIA RELIGIOSA

Antonio Baptista Gonçalves

UM DiREITO SEM ESTADO? DiREITOS humanos E A FORMAÇÃo DE UM NOVO QUADRo NORMATIVO GLOBAL .87

Anderson Vichinkeski Teixeira e Rafael Köche

\section{Direito Humanitário}

The U.N. Standard Minimum Rules for the Treatment of Prisoners and North Korea: How North Korea is Violating these Rules with its Operation of the Yodok Concentration CAMP.

Tom Theodore Papain

U.S. Institutionalized Torture with Impunity: Examining Rape and Sexual Abuse in Custody Through the ICTY JurisprudenCE. 126 Allison Rogne 
Abduction, Torture, Interrogation: An Argument Against Extraordinary RendiTION

Kaitlyn E. Tucker

United States and European Union approaches to the death penalty: America SHOULD CONSIDER A NEW PERSPECTIVE 155 Katie R Hill

Tudo DE NOVO NO FRONT: MONUSCO, UMA NOVA ERA NAS PEACEKEEPING OPERATIONS? .169 Priscila Fett

A ADMINISTRAÇÃo DE TERRITÓRIOS OCUPADOS: INDETERMINAÇÃO DAS NORMAS DE DIREITO INTERNACIONAL HUMANITÁRIO?. 184 João Henrique Ribeiro Roriz, Fabia Fernandes Carvalho Veçoso e Lucas da Silva Tasquetto

THE (IN)APPLICABILITY OF THE STATUTE OF REFUGEES TO ENVIRONMENTALLY DISPLACED PERSONS 197 Maria Cláudia da Silva Antunes de Souza e Lucas de Melo Prado

\section{Sistema Interamericano de Direitos Humanos}

A contribuição da Comissão Interamericana de Direitos Humanos para o acesso À jus-

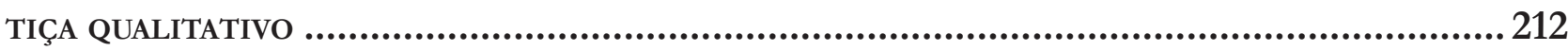
Márcio Antônio de Oliveira Filho, Ana Caroline Portes de Oliveira, Jéssica Galvão Chaves e Warlen Soares Teodoro

A executividade das sentenças da Corte Interamericana de Direitos Humanos no

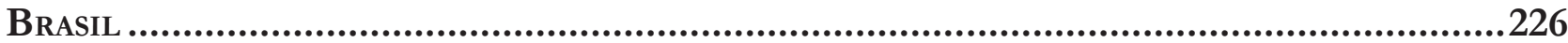

Augusto César Leite de Resende

A efetividade do ativismo jurídico transnacional no Sistema Interamericano de DiREITOS HuMANOS: UMA ANÁLISE A PARTIR DE CASOS CONTRA O BRASIL .................................238 Renata Mantovani de Lima e Lucélia de Sena Alves

O Processo e o Direito Coletivo no Sistema Interamericano de Direitos Humanos: UMA ANÁLISE COM BASE NA JURISPRUDÊNCIA INTERNACIONAL ...........................................250 Laercio Dias Franco Neto e Dafne Fernandez de Bastos 
CORTE INTERAMERICANA DE DIREITOS HUMANOS: OPINIÃo CONSULTIVA 4/84 - A MARGEM DE

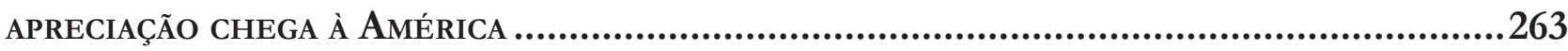

Paloma Morais Corrêa

A "PLENA" LIBERDADE DE EXPRESSÃo E OS DIREITOS HUMANOS: ANÁLISE DA JURISPRUDÊNCIA DA Corte InTeramericana de Direitos Humanos e o Julgamento da ADPF 130 281 Natália Paes Leme Machado

A proteção do meio ambiente no Sistema Interamericano de Direitos Humanos a parTIR DO DIREITO À EDUCAÇÃO.

Augusto César Leite de Resende

Parameters and procedures of the Inter-American System of Human Rights in CHILDREN'S RIGHTS VIOLATION LAWSUITS

Maria Guiomar da Cunha Frota e Pedro Alves Barbosa Neto

Poverty as a Violation of Human Rights: THE CASE OF STREET CHILDREN IN GUATEMALA AND BRAZIL

Paloma Morais Correa

\section{Proteção Internacional dos Direitos Humanos e o Direito Brasileiro}

A LEI N. 11.340/06 E SUAS REPERCuSSõES No CONTRATO INDIVIDUAL DE TRABALHo. Humberto Lima de Lucena Filho e Waldeny Pereira Filho

ORIENTAÇÃo SEXUAL E DISCRIMINAÇão NO AMBIENTE LABORAL

Glaucia Fernanda Oliveira Martins Batalha

NORMAS EDITORIAIS 


\title{
A administração de territórios ocupados: indeterminação das normas de direito internacional humanitário?
}

\section{The administration of occupied territories and the indeterminacy of international humanitarian law*}

\author{
João Henrique Ribeiro Roriz ${ }^{* *}$ \\ Fabia Fernandes Carvalho Veçoso*** \\ Lucas da Silva Tasquetto ${ }^{* * *}$
}

\begin{abstract}
And let not one of you think that in having these things he has what does not belong to him; for it is a law established for all time among all men that when a city is taken in war, the persons and the property of the inhabitants thereof belong to the captors. It will, therefore, be no injustice for you to keep what you have, but if you let them keep anything, it will be only out of generosity that you do not take it away. Xenofonte, Cyropaedia, 7.5.73.
\end{abstract}

* Recebido em 23/08/2012 Aprovado em 26/01/2013

** Professor no curso de Relações Internacionais, Universidade Federal de Goiás. Doutor em direito internacional pela Universidade de São Paulo. Mestre em direito internacional pela London School of Economics and Political Science. Email: joao.roriz@gmail.com

*** Professora da Faculdade de Direito do Sul de Minas. Doutora e Mestre em Direito Internacional pela Universidade de São Paulo. Email: fabia.vecoso@gmail.com

**** Doutorando em Relações Internacionais na Universidade de São Paulo (IRI/USP). Bolsista da Fundação de Amparo à Pesquisa do Estado de São Paulo. Email: lucastasquetto@ gmail.com

\section{Resumo}

O objetivo deste artigo é analisar as normas de direito internacional humanitário relativas à administração de territórios ocupados. Primeiro, apresentamos a noção de "território ocupado" no direito internacional humanitário segundo os principais tratados sobre o tema, assim como as principais decisões de tribunais internacionais sobre a matéria. Em seguida, discutimos especificamente a Regulação 43 das Regulações da Haia de 1907, que dispõe sobre os direitos e deveres do Estado ocupante. Logo após, analisamos o caso da ocupação liderada pelos Estados Unidos e pelo Reino Unido no Iraque após a guerra em 2003, que promoveu uma série de reformas liberais na economia iraquiana. À luz das regulações relativas à administração de territórios ocupados, buscamos responder se: (i) as transformações econômicas promovidas pelas potências ocupantes foram voltadas para a restauração e asseguração da ordem e da vida públicas no Iraque; e (ii) se houve um impedimento absoluto para se manter a legislação doméstica econômica. Concluímos que indeterminações das normas de direito internacional humanitário relativas à ocupação militar de territórios, impossibilitam uma resposta exata que evite o abuso promovido por aqueles que têm mais poder. $\mathrm{O}$ discurso em defesa das normas de direito internacional humanitário está arquitetado na premissa de que é possível reduzir o sofrimento humano em conflitos armados. Todavia, restou claro que esse sistema apresenta diversas lacunas que permitem a exploração por parte daqueles que tentam encobrir suas intenções com o manto da legalidade.

Palavras-chave: Direito internacional humanitário. Ocupação territorial. Iraque. 


\section{Abstract}

The aim of this paper is to analyze the rules of international humanitarian law concerning the administration of the occupied territories. First, we introduce the notion of "occupied territory" in international humanitarian law with reference to the main treaties on the subject, as well as the major decisions of international tribunals. Then, we examine specifically regulation 43 of the 1907 Hague Regulations, which provides for the rights and duties of the occupying state. Soon after, we investigate the specific case of the occupation led by the U.S. and UK in Iraq after the war in 2003 which promoted a number of liberal reforms in the Iraqi economy. In light of the regulations regarding the administration of the occupied territories, we seek to answer whether (i) the economic transformations sponsored by the occupying powers were aimed at restoring and ensuring public order and life in Iraq, and (ii) if there was an absolute impediment in keeping economic domestic legislation. We conclude that the indeterminacies of international humanitarian law regarding the military occupation of territories preclude an exact answer that could prevent abuse directed by those who have more power. The discourse in defense of international humanitarian law is structured on the premise that it is possible to reduce human suffering in armed conflicts. However, it remains clear that this system has many loopholes that allow exploitation by those who try to cover up their intentions with the mantle of legality.

Keywords: International humanitarian law. Territorial occupation. Irak.

\section{INTRODUÇÃo}

O presente artigo pretende fazer uma leitura crítica das normas de direito internacional humanitário relativas à administração de territórios ocupados. Em específico, analisamos como tais normas podem conter indeterminações que favoreçam uma das partes envolvidas, a "potência ocupante", deixando pouco espaço para o desenvolvimento dos interesses do território ocupado. Nossa hipótese é que a gramática das regras relativas à atividade legislativa e à administração da ordem da vida pública nos territórios ocupados permite a adoção de amplas medi-

1 "Potência ocupante" significa o Estado que ocupa o território invadido. É o termo utilizado nos documentos de direito internacional humanitário, como as Convenções de Genebra de 1949. das por parte daqueles responsáveis pela condução da vida pública no território militarmente ocupado.

Centramos nossa atenção nos limites que o próprio direito internacional humanitário relativo a ocupações territoriais se propõe para impedir o abuso de poder da potência ocupante, mas que, no entanto, parece depender de pontos de interpretação extremamente amplos, graças ao caráter indeterminado da linguagem do direito internacional. As principais normas que regulam as atividades das potências ocupantes em territórios ocupados foram formuladas há mais de um século, nas Regulações da Haia de 1907. No entanto, continuam sendo os dispositivos mais utilizados na análise das ocupações militares, como nos casos da Palestina, de guerras africanas (como a ocupação da República Democrática do Congo) e europeias (a ocupação sérvia na Bósnia-Herzegovina). Também têm sido comuns referências ao direito da ocupação militar de territórios em casos analisados por tribunais internacionais, como a Corte Internacional de Justiça e o primeiro caso do Tribunal Penal Internacional.

Como estudo de caso, centraremos nossa atenção na ocupação militar liderada pelos Estados Unidos e pelo Reino Unido no Iraque, ocorrida entre meados de maio de 2003 a junho de 2004. Como será apresentado, tal ocupação ilustra muito bem a forma pela qual as normas humanitárias podem ser interpretadas com ampla discricionariedade e, como potências ocupantes, podem se utilizar dessa margem para implementar profundas reformas. Antes de expormos o caso iraquiano, faremos uma análise mais detida sobre os principais dispositivos relativos à administração de territórios ocupados, as regulações 42 e 43 das Regulações da Haia de 1907, com referências a outros dispositivos relevantes.

\section{A NOÇÃo DE TERRITÓRIO OCUPADO}

Na Regulação 42 das Regulações da Haia de 1907, encontramos os elementos utilizados na noção de "território ocupado". Segundo esse dispositivo, um território é considerado ocupado "[...] quando se encontra de fato sob a autoridade do exército inimigo". Complementa ainda o mesmo texto em apreço: “[...] a ocupação se estende somente ao território onde tal autoridade foi estabelecida e pode ser exercida". ${ }^{2} \mathrm{O}$ dispositivo deixa

2 "Un territoire est considéré comme occupé lorsqu'il se trouve placé de fait sous l'autorité de l'armée ennemie. L'occupation ne s'étend qu'aux territoires où cette autorité est établie et en mesure de 
claro que a capacidade de controle territorial é o requisito fundamental para a caracterização de território ocupado: a autoridade de fato deve ser constituída pelo país invasor com controle territorial por meio da presença física de suas tropas e, à medida que isso ocorre, o invasor se vê constrangido pelas responsabilidades de uma potência ocupante de acordo com o direito internacional humanitário. Tal interpretação é reiterada pela segunda parte do texto normativo que versa que o direito relativo à ocupação não é aplicável em áreas onde ainda ocorrem batalhas, i.e., áreas onde não foi estabelecida uma autoridade permanente capaz de exercer controle efetivo.

Os documentos posteriores às Regulações da Haia de 1907 não divergem da definição de ocupação adotada por esse instrumento. A questão que se coloca é se a Convenção de Genebra IV de 1949 amplia a definição de ocupação quando trata da proteção de civis, especificamente no lapso temporal entre o fim das hostilidades e o efetivo controle territorial exigido pela Regulação 42 das Regulações de 1907. Esse foi o entendimento expresso no comentário da Cruz Vermelha ao art. $6^{\circ}$ da Convenção IV de 1949: de certa forma essa convenção amplia o significado de ocupação ao não exigir que o invasor tenha controle efetivo do território para a aplicação das normas humanitárias em relação à proteção de civis. ${ }^{3}$ Esse também foi o entendimento adotado no caso Naletilic \& Martinović, no Tribunal Penal Internacional para a ex-Iugoslávia. ${ }^{4}$

s'exercer" CONVENTION (IV) concernant les lois et coutumes de la guerre sur terre et son Annexe: Règlement concernant les lois et coutumes de la guerre sur terre. Haia, 18 de outubro de 1907. Regulação 42. Disponível em: <http://www.icrc.org/dih.nsf/full/195>. Acesso em: 14 set. 2011.

3 'It follows from this that the word 'occupation', as used in the Article, has a wider meaning than it has in Article 42 of the Regulations annexed to the Fourth Hague Convention of 1907. So far as individuals are concerned, the application of the Fourth Geneva Convention does not depend upon the existence of a state of occupation within the meaning of the Article 42 referred to above. The relations between the civilian population of a territory and troops advancing into that territory, whether fighting or not, are governed by the present Convention. There is no intermediate period between what might be termed the invasion phase and the inauguration of a stable regime of occupation." Pictet, Jean. Commentary on Geneva Convention IV Relative to the Protection of Civilian Persons in Time of War. Genebra: ICRC, 1958. p. 60.

4 "The application of the law of occupation as it effects "individuals" as civilians protected under Geneva Convention IV does not require that the occupying power have actual authority. For the purposes of those individuals' rights, a state of occupation exists upon their falling into "the hands of the occupying power." TRIBUNAL PENAL INTERNACIONAL PARA A EX-IUGOSLÁVIA.
De qualquer forma, o dispositivo mais invocado na jurisprudência de tribunais internacionais que analisaram situações relativas a essa matéria continua sendo a Regulação 42 das Regulações da Haia de 1907. Um exemplo disso é a posição dos juízes da Corte Internacional de Justiça nos casos Legal Consequences of the Construction of a Wall in the Occupied Palestinian Territory, e Armed Activities on the Territory of the Congo, que além de retomarem essa definição, ainda observam que tal dispositivo representa uma regra costumeira do direito internacional. ${ }^{5}$ No caso Lubanga, o primeiro do Tribunal Penal Internacional, os juízes também se referem à noção de território ocupado segundo a Regulação $42 .{ }^{6}$ Da mesma forma, no caso Naletilić \& Martinović, além de reiterar a definição supraexposta, os juízes do TPII esclareceram que a ocupação é "[...] um período transicional após a invasão e que precede o acordo do fim das hostilidades".?

É importante salientar que, para as interpretações mais técnicas do direito internacional humanitário, "ocupação territorial" não se confunde com "invasão militar". No caso Hostages, julgado por um tribunal militar estadunidense em Nuremberg na Alemanha, contrastaram-se as noções de "ocupação" e "invasão", o que contribui para a compreensão do sentido do primeiro termo:

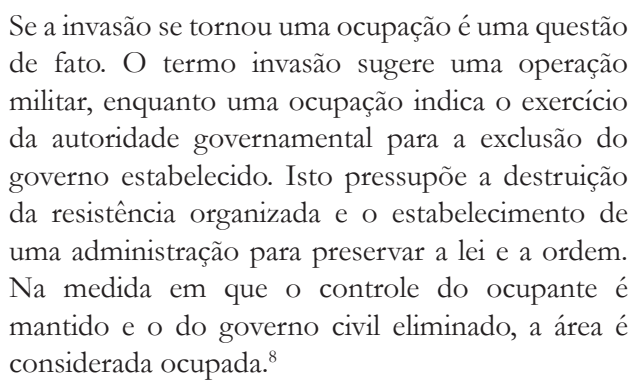

Prosecutor v. Naletilic \& Martinović (IT-98-34-T): "Tuta and Štela", Judgment. J. em: 31 de março de 2003, para. 221..

5 CORTE INTERNACIONAL DE JUSTIÇA. Legal Consequences of the Construction of a Wall in the Occupied Palestinian Territory: Advisory Opinion. J. em 9 de julho de 2004. Haia: ICJ Reports, 2004. p. 136. parágrafo 78; CORTE INTERNACIONAL DE JUSTIÇA. Congo, Democratic Republic of the Congo v. Uganda : armed activities on the territory of the, Judgment. J. em: 19 de dezembro de 2005. Haia: ICJ Reports 2005. p. 168. parágrafo 172.

6 TRIBUNAL PENAL INTERNACIONAL. Prosecutor $v$. Thomas Lubanga Dyilo. Judgment pursuant to Article 74 of the Statute (ICC01/04-01/06). J. em: 14 de março de 2012, para. 542.

7 "Occupation is defined as a transitional period following invasion and preceding the agreement on the cessation of the hostilities". TRIBUNAL PENAL INTERNACIONAL PARA A EX-IUGOSLÁVIA. Prosecutor v. Naletilic \& Martinović (IT-98-34-T) "Tuta and Štela", Judgment. J. em: 31 de mar. 2003, p. 214.

8 "Whether an invasion has developed into an occupation is a question of fact. The term invasion implies a military operation while an occupation indicates the exercise of governmental authority to the exclusion of the established 
Além de esclarecer o sentido próprio de uma ocupação, essa passagem relembra a distinção entre o ato de invasão militar e a prática posterior de ocupação territorial. Não necessariamente todo território invadido se torna um território ocupado: além de os objetivos dessas duas operações serem distintos, também são suas consequências. Tendo em vista a contínua presença da população civil no território ocupado, o invasor deve zelar pela manutenção da ordem ao substituir interinamente as instituições públicas - ou seja, o invasor passa a ser o administrador daquele território, com ônus e vantagens. Ainda sobre a relação entre a invasão vis-à-vis a ocupação, devemos relembrar que as razões que levam um país a ocupar o território de outro não são relevantes para a aplicação das normas humanitárias. Da forma que a aplicação do direito internacional humanitário foi pensada, não se discute a legalidade da invasão e a posterior ocupação - mas sim sua existência. Ou seja, as normas relativas à ocupação são aplicadas independentemente do território ter sido ocupado por meio de uma agressão ilegal ou fruto de uma ação militar de legítima defesa de acordo com o art. 51 da Carta da ONU.

Visto a complexidade de se verificar na prática quando um território é considerado ocupado nos termos da Regulação 42, o exposto no caso Naletilić \& Martinović oferece um guia bastante útil:

(i) a potência ocupante deve estar em uma posição
em que possa substituir sua própria autoridade por
aquela das autoridades dos ocupados, que devem
ser incapazes de funcionar publicamente; (ii) as
forças inimigas se renderam, foram derrotadas ou
se retiraram. A este respeito, áreas onde ocorrem
batalhas não podem ser consideradas território
ocupado. No entanto, resistência local esporádica,
mesmo bem-sucedida, não afeta a realidade de
ocupação; (iii) a potência ocupante tem força
presente suficiente, ou a capacidade de enviar
tropas dentro de um tempo razoável para exercer
a autoridade; (iv) uma administração temporária foi
estabelecida no território; (v) a potência ocupante
promulgou e efetivou regras para a população civil. ${ }^{\circ}$

government. This presupposes the destruction of organised resistance and the establishment of an administration to preserve law and order. To the extent that the occupant's control is maintained and that of the civil government eliminated, the area will be said to be occupied." (tradução nossa). U.S. Military Tribunal. United States of America v Wilhelm List et al (Judgment). Case $\mathrm{N}^{\circ}$ 7, J. em: 19 de fevereiro de 1948. XI Trials of War Criminals before the Nürnberg Military Tribunals under Control Council Lawn, n. 10. Washington: US GPO, p. 1243.

9 "The occupying power must be in a position to substitute its own authority for that of the occupied authorities, which must have been rendered incapable of functioning publicly; the enemy's forces have surrendered, been defeated or withdrawn. In this respect, battle areas may not be considered as occupied territory. However, sporadic
Em suma, o "mecanismo de aplicação" das normas de direito internacional humanitário relativo à ocupação é acionado à medida que a potência ocupante tem controle sobre o território, i.e., quando exerce sua autoridade. Segundo o direito internacional humanitário, é irrelevante para a aplicação das normas relativas à ocupação se a potência ocupante reconhece seu status como tal. ${ }^{10}$

\section{A Regulação 43: DiREITOS E deVERES dA PO- TÊNCIA OCUPANTE}

A análise da Regulação 43 das Regulações da Haia de 1907 é um dos pontos cardeais de qualquer apreciação sobre as normas relativas a ocupações militares. Para Benvenisti, esse dispositivo é a "essência" do direito da ocupação, além de ser quase uma "miniconstituição", já que prescreve tanto os deveres da potência ocupante quanto seus direitos. ${ }^{11} \mathrm{Na}$ Conferência de 1907, foram adotadas duas versões das regulações, uma em francês e outra em inglês - sendo a primeira a versão autêntica e mandatória. O texto em francês da Regulação 43 relata que:

L'autorité du pouvoir légal ayant passé de fait entre les mains de l'occupant, celui-ci prendra toutes les mesures qui dépendent de lui en vue de rétablir et d'assurer, autant qu'il est possible, l'ordre et la vie publics en respectant, sauf empêchement absolu, les lois en vigueur dans le pays.

A versão inglesa ${ }^{12}$ não é exatamente igual à francesa, mas voltaremos a esse ponto depois. Apresentamos

Local resistance, even successful, does not affect the reality of occupation; the occupying power has a sufficient force present, or the capacity to send troops within a reasonable time to make the authority of the occupying power felt; a temporary administration has been established over the territory; the occupying power has issued and enforced directions to the civilian population." (as notas de rodapé foram omitidas) (tradução nossa) TRIBUNAL PENAL INTERNACIONAL PARA A EX-IUGOSLÁVIA. Prosecutor v. Naletilic \& Martinović (IT-98-34-T) "Tuta and Štela", Judgment. J. em: 31 de março de 2003, para. 217.

10 "Under customary international law, these were therefore occupied territories in which Israel had the status of occupying Power. Subsequent events in these territories, as described in paragraphs 75 to 77 above, have done nothing to alter this situation. All these territories (including East Jerusalem) remain occupied territories and Israel has continued to have the status of occupying Power." (grifo nosso) CORTE INTERNACIONAL DE justiça. Legal Consequences of the Construction of a Wall in the Occupied Palestinian Territory: Advisory Opinion. Haia: ICJ Reports, 2004. p. 136-78.

11 BENVENISTI, Eyal. The International Law of Occupation. 2. ed. Princeton: Princeton University Press, 2004. p. 7-9.

12 A versão em inglês: "Regulation 43. The authority of the legitimate power having in fact passed into the hands of the occupant, the latter shall take all the measures in his power to restore and ensure, as far as possible, public order and safety, while respecting, unless absolutely prevented, the laws in force in the country." 
uma tradução livre para fins didáticos (é notável que o Brasil tenha promulgado um decreto sobre esse tratado com o texto em francês, sem uma tradução oficial): ${ }^{13}$

Tendo a autoridade do poder legal passado de fato para as mãos do ocupante, esse deve tomar todas as medidas ao seu alcance para restaurar e assegurar, na medida do possível, a ordem e vida públicas, respeitando, salvo impedimento absoluto, as leis em vigor do país.

Há alguns pontos controversos sobre esse dispositivo que merecem ser sopesados em detalhe para os propósitos do nosso estudo; mas, antes de abordarmos as obrigações específicas dessa regulação, faremos algumas considerações iniciais de caráter mais geral a seu respeito. Quando se consulta os travaux préparatoires das Regulações da Haia de 1907, chegamos aos dispositivos $2^{\circ}$ e $3^{\circ}$ da Declaração de Bruxelas de 1874:14

2. L'autorité du pouvoir légal étant suspendue et ayant passée de fait entre les mains de l'occupant, celui-ci prendra toutes les mesures qui dépendent de lui en vue de rétablir et d'assurer, autant qu'il est possible, l'ordre et la vie publique.

3. À cet effet, il maintiendra les lois qui étaient en vigueur dans le pays en temps de paix, et ne les modifiera, ne les suspendra ou ne les remplacera que s’il y a nécessité. ${ }^{15}$

A partir de tais textos fica claro que duas são as obrigações expressas na Regulação 43: (i) restaurar e assegurar a vida e a ordem pública no território ocupado (na medida do possível); e (ii) respeitar as leis vigentes no território ocupado (a não ser que um impedimento absoluto exista). Tais obrigações não devem ser entendidas separadamente. No texto da Regulação 43 o uso das palavras "en respectant" ("while respecting", na versão inglesa), que podemos traduzir como "respeitando", vincula as duas obrigações, i.e., as medidas adotadas pela potência ocupante devem contemplar simultaneamente as obrigações (i) e (ii).

Os delegados na Conferência da Haia que negociavam as regulações optaram pela unificação dos textos em um único dispositivo, a Regulação 43, graças a uma

13 Ver: Dec. 10.719 de 04 de fevereiro de 1914.

14 Estes dispositivos são similares aos artigos 43 e 44 do Manual de Oxford de 1880 Institut de Droit International. The Laws of War on Land. Oxford, 9 de setembro de 1880. Disponível em: <http:/ / www.icrc.org/ ihl.nsf/FULL/140?OpenDocument>. Acesso em: 14 set. 2011.

15 PROJET d'une Déclaration Internationale concernant les Lois et Coutumes de la Guerre, 1874, 65 British and Foreign State Papers. p. 1059-1060 apud DINSTEIN, Yoram. Legislation Under Article 43 of the Hague Regulations: Belligerent Occupation and Peacebuilding. $\mathrm{Oc}$ casional Paper Series: Program on Humanitarian Policy and Conflict Research, Harvard University, n. 1, nov. 2004. p. 3. Disponível em: < http:// www.hpcr.org/publications/ops.php>. Acesso em: 11 fev. 2012. percepção de que o parágrafo $3^{\circ}$, quando separado, daria poderes legislativos excessivamente amplos à potência ocupante. ${ }^{16}$ Essa passagem histórica demonstra a preocupação dos representantes estatais em não ampliar demasiadamente os poderes de um Estado que mantém outro sob o seu jugo.

Analisaremos em seguida as duas obrigações referidas na Regulação 43 para, posteriormente, expormos um caso que elucida questões problemáticas, o da ocupação do Iraque em 2003.

\subsection{Restaurar e assegurar a ordem de vidas públicas}

Se revisitarmos os travaux préparatoires da Conferência na Haia em 1907, poderemos verificar os significados que os delegados de então davam aos termos "ordem" ("l'ordre") e "vida pública" ("vie publique"); enquanto o primeiro tinha o sentido de "segurança geral", o segundo tinha uma conotação de "funções sociais e transações comuns que constituem o cotidiano". ${ }^{17}$

Há relativo consenso jurisprudencial ${ }^{18}$ e entre comentadores especializados ${ }^{19}$ sobre o problema da tradução da Regulação 43, em específico da expressão francesa "l'ordre et la vie publics". Na versão inglesa, essa expressão apareceu como "public order and safety", o que destoa do significado original. A palavra inglesa "safety", além de não ser mencionada na versão francesa, não

16 BENVENISTI, Eyal. The International Law of Occupation. 2. ed, Princeton: Princeton University Press, 2004. p. 8.

17 " $M$. Le baron Lambermont demande ce qu'il faut entendre par ordre. I1 y a ordre matériel, civil, social politique. $M$. le délégué de Belgique présume qu'on a seulement en vue la sécurité ou la sûreté générale; quant à l'expression 'vie publique', il pense qu'il s'agit des fonctions sociales, des transactions ordinaires, qui constituent la vie de tous les jours. La commission interprète ce mot dans le même sens que M. le baron Lambermont. On mettra: 'l'ordre et la vie publics'." MINISTERE DES AFFAIRES ÉTRANGÈRES. Actes de la Conference de Bruxelles de 1874, Paris,[s.n] 1874; apud Schwenk, Edmund H. Legislative Power of the Military Occupant Under Article 43, Hague Regulation. Yale Law Journal, Yale, v. 54, p. 393-416, 1945. p. 398.

18 Por exemplo: SUPREMA CORTE DE ISRAEL, Christian Society for the Holy Places v Minister of Defence, 1971; apud Sassòli, Marco. Legislation and Maintenance of Public Order and Civil Life by Occupying Powers. European Journal of International Law. v. 16, n. 4, pp. 661-694, 2005, p. 664. 19 BENVENISTI, Eyal. The International Law of Occupation. 2. ed, Princeton: Princeton University Press, 2004. p. 9; GREENWOOD, Christopher. The Administration of Occupied Territory in International Law. In: Playfair, Emma (ed.) International Law and the Administration of Occupied Territories: Two decades of Israeli Occupation of the West Bank and Gaza Strip. Oxford: Clarendon, 1992. p. 246; DINSTEIN, Yoram. The International Law of Belligerent Occupation. Nova York: Cambridge University Press, 2009. p. 89. 
contempla a acepção mais ampla de "vie", no sentido de "vida pública", conforme expusemos. Essa observação se faz importante na medida em que o sentido da versão autêntica e mandatória do dispositivo em francês é muito mais amplo do que a versão traduzida para o inglês - uma versão, às vezes utilizada tanto por comentadores quanto por aplicadores do direito internacional humanitário. Ademais, a errônea tradução reforça a interpretação daqueles que querem ressaltar a obrigação - assim como as prerrogativas - da potência ocupante em matéria de segurança pública. A leitura de John Yoo, um servidor do Departamento de Justiça nos EUA à época da invasão no Iraque sobre a Regulação 43 é esclarecedora quanto ao uso enviesado desse dispositivo. ${ }^{20}$

Os comentadores especializados discordam sobre o significado das palavras "restaurar" (do francês "rétablir") e "assegurar" (do francês "assurer"). Como interpretado no caso Jamit Askan da Suprema Corte israelense, os dois termos não são sinônimos: enquanto o primeiro denota o estabelecimento da ordem e da vida pública (caso rompida), o segundo significa a garantia da existência contínua da ordem e da vida públicas. ${ }^{21}$ Assim, uma interpretação possível é que a potência ocupante deve não apenas reparar a organização social no território ocupado, mas também assegurar que ela será mantida. O problema principal é como a potência ocupante irá desenvolver tais atividades e, mais especificamente, quais são os limites para suas ações e ainda, se o ocupante tem prerrogativa de quais políticas serão adotadas.

O limite à obrigação de restaurar e assegurar a ordem e a vida públicas reside na oração "autant qu'il est possible", ou seja, tal obrigação deve ser cumprida "na medida do possível". Essa relativização da norma faz a obrigação perder força cogente, além de significar que a obrigação em análise é de meios e não de resultados, ${ }^{22}$ i.e., a potên-

20 "The text of Article 43 of the Hague Regulations provides ample authority to the United States to change Iraqi law, including the fundamental change of Iraqi government institutions. Article 43 empowers an occupant to modify an occupied nation's laws if it is necessary to restore and ensure 'public order and safety." (grifo nosso). YOO, John. Iraqi Reconstruction and the Law of Occupation. University of California Davis Journal of International Law and Policy. v.11, n. 7, p. 7-22, 2004. p 16.

21 SUPREMA CORTE DE ISRAEL. Jamait Askan et al., v. IDF Commander of Judea and Samaria et al. (HCJ 393/82), 1982; apud DINSTEIN, Yoram. The International Law of Belligerent Occupation. Nova York: Cambridge University Press, 2009. p. 91.

22 Sassòli, Marco. Legislation and Maintenance of Public Order and Civil Life by Occupying Powers. European Journal of International Law. v. 16, n. 4, p. 661-694, 2005. p. 664. cia ocupante deve almejar atingir os objetivos de ordem e de vida públicas, e empregar meios para isso.

\subsection{Respeitando as leis vigentes no território}

Passemos então à obrigação de respeito às leis vigentes no país ocupado, ou como versa o texto autêntico em francês: "[...] en respectant, sauf empêchement absolu, les lois en vigueur dans le pays". O verbo "respeitar", na gramática da Declaração de Bruxelas, pode ser interpretado como a obrigação das potências de manter a legislação válida e não modificá-la, suspendê-la ou substituí-la por outras normas. ${ }^{23}$ Ainda que o texto do dispositivo em apreço se refira especificamente às leis que estavam em vigor até o momento da ocupação, há interpretações que entendem que o soberano deslocado tem o direito de continuar legislando em relação ao território ocupado, mesmo que a potência ocupante não tenha a obrigação de respeitar tais normas. ${ }^{24}$ Esse é um entendimento extensivo, pois versa o dispositivo apenas sobre a legislação em vigor. De qualquer maneira, e sem entrar no mérito da questão se pode ou não o soberano deslocado legislar no território ocupado alhures, a mera propositura da questão reforça a leitura de que o poder de legislar não é concedido à potência ocupante de forma total.

Em termos técnicos, o cerne da polêmica reside na expressão "sauf empêchement absolu"- ou "salvo impedimento absoluto" - situação-limite na qual é facultada às potências ocupantes se eximirem da obrigação de observância da legislação local. Essa é a exceção; em regra, a potência ocupante não deve alterar a legislação local nem legislar sobre matérias ainda não reguladas.

Qual seria, portanto, o significado de "sauf empêchement absolu"? Uma interpretação consagrada expõe que a expressão reescreve a palavra "nécessitê" do art. $3^{\circ}$ da Declaração de Bruxelas e que significaria "necessidade absoluta". ${ }^{25}$ Segundo essa ponderação, não há que se

23 DINSTEIN, Yoram. The International Law of Belligerent Occupation. Nova York: Cambridge University Press, 2009. p. 108.

24 DINSTEIN, Yoram. The International Law of Belligerent Occupation. Nova York: Cambridge University Press, 2009. p. 108.

25 'It is therefore submitted that the term 'empêchement absolu' means nothing but 'absolute necessity'. This interpretation is warranted by the historical fact that the term is merely a rephrasing of the word 'necessity' in Article 3 of the Declaration of Brussels. As a result, the occupant, in restoring public order and civil life, must respect the existing law of the occupied country unless he is prevented from doing so by 'absolute necessity'." Schwenk, Edmund $\mathrm{H}$. Legislative Power of the Military Occupant Under Article 43, Hague Regulation. Yale Law Journal, Yale, v. 54, p. 393-416, 1945. p. 401. 
confundir a expressão em análise com o interesse militar da potência ocupante, já que a restauração da ordem e da vida públicas se destina à população civil. ${ }^{26}$ Ainda que essa interpretação pareça ser a mais aceita pelos comentadores, a ideia de "necessidade" tem um tom menos enfático que "impedimento absoluto".

No caso Christian Society for the Holy Places, relativo à alteração de uma lei trabalhista da Jordânia durante a ocupação israelense da Cisjordânia, a Suprema Corte de Israel considerou que o termo "salvo impedimento absoluto" deveria ser interpretado vis-à-vis as obrigações da potência ocupante com a população dos territórios ocupados. ${ }^{27} \mathrm{Ou}$ seja, os interesses da população civil deveriam direcionar a utilização da prerrogativa de legislar - não apenas os interesses da potência ocupante. Ainda assim, as medidas legislativas devem atender o critério da necessidade absoluta para que não sejam consideradas ultra vires. As alterações conduzidas pela Alemanha na legislação da Bélgica ocupada durante a Primeira Guerra Mundial são um exemplo. Quer tenham sido adotadas em prol dos interesses belgas ou dos interesses teutos, a vasta legislação produzida pela Alemanha para a Bélgica em questões relativas ao comércio, à educação, à saúde, à língua, aos negócios e às diversas atividades produtivas, dificilmente poderia ser considerada dentro de um quadro de necessidade absoluta, porquanto sua legalidade pode ser contestada. ${ }^{28}$

Um caminho para compreender essa noção pode ser a leitura conjunta do art. 43 com o art. 64 da IV Convenção de Genebra de 1949, a saber:

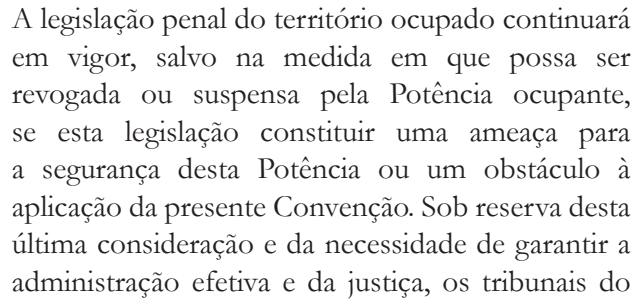

26 Schwenk, Edmund H. Legislative Power of the Military Occupant. Under Article 43, Hague Regulation. Yale Law Journal, Yale, v. 54 , p. 393-416, 1945. p. 400.

27 Suprema Corte de Israel, The Christian Society for the Holy Places v. Minister of Defense (HC 337/71), 1971; apud DINSTEIN, Yoram. Legislation Under Article 43 of the Hague Regulations: Belligerent Occupation and Peacebuilding. Occasional Paper Series, Program on Humanitarian Policy and Conflict Research, Harvard University, n. 1, nov. 2004. p. 8-10. Disponível em: <http://www.hpcr.org/publications/ops.php>. Acesso em: 11 maio 2011.

28 Schwenk, Edmund H. Legislative Power of the Military Occupant Under Article 43, Hague Regulation. Yale Law Journal, Yale, v. 54, p. 393-416, 1945. p. 407. território ocupado continuarão a funcionar para todas as infrações previstas por esta legislação.

A Potência ocupante poderá, contudo, submeter a população do território ocupado às disposições que são indispensáveis para lhe permitir desempenhar as suas obrigações derivadas da presente Convenção e garantir a administração regular do território, assim como a segurança quer da Potência ocupante, quer dos membros e dos bens das forças ou da administração da ocupação, assim como dos estabelecimentos e linhas de comunicação utilizadas por ela. (grifo nosso).

A análise conjugada dos dois dispositivos delineia mais precisamente a noção de "necessidade", caso aceitemos sua aproximação com a ideia de "impedimento absoluto". No primeiro parágrafo, há a exigência de não alterar a legislação penal do país ocupado, a não ser em caso de risco para a aplicação da Convenção. De acordo com o segundo parágrafo, que parece ser relativo ao direito em geral, ${ }^{29}$ as potências ocupantes podem legislar quando indispensável para sua segurança, para os fins da Convenção e para a administração regular do território. Para Pictet, os dois parágrafos devem ser entendidos em conjunto, o que sugere que as potências ocupantes têm que respeitar todas as leis do território e não só as penais. ${ }^{30}$

Há outras interpretações quanto à relação da Regulação 43 das Regulações de 1907 com o art. 64 da Convenção de $1949 ;^{31}$ todavia, parece-nos mais acertada a leitura apresentada anteriormente, na qual se verifica a impossibilidade de alteração de dispositivos de caráter penal do país ocupado, a não ser quando haja incompatibilidade com a Convenção de Genebra e improbabilidade de outras alterações, salvo quando existir dispositivos que ameacem a segurança dos ocupantes, a aplicação da Convenção ou a administração do terri-

29 BENVENISTI, Eyal. The International Law of Occupation. 2. ed. Princeton: Princeton University Press, 2004. p. 101.

30 Pictet, Jean. Commentary on Geneva Convention IV Relative to the Protection of Civilian Persons in Time of War. Genebra: ICRC, 1958. p. 335.

31 Ao analisar a Regulação 43 das Regulações de 1907 em conjunto com o art. 64 da Convenção de 1949, Dinstein identifica três dimensões sobre a ideia de "necessidade": (i) a primeira (e mais importante para esse autor) é a prerrogativa fundamental das potências ocupantes de eliminar qualquer ameaça direta a sua segurança; (ii) a segunda é a obrigação de cumprir as exigências das Convenções de Genebra; e (iii) finalmente, a necessidade de assegurar a "administração ordenada" do território ocupado. DINSTEIN, Yoram. Legislation Under Article 43 of the Hague Regulations: Belligerent Occupation and Peacebuilding. Occasional Paper Series, Program on Humanitarian Policy and Conflict Research, Harvard University, n. 1, nov. 2004. p. 6-8. Disponível em:<http://www.hpcr.org/publications/ops.php>. Acesso em: 11 fev.2012. 
tório. É principalmente nessa última questãoque reside um dos pontos mais frágeis das regras apresentadas até agora. A noção de indispensabilidade, que limita o poder da potência ocupante de legislar para o país ocupado para fins de administração territorial, permite ampla margem de interpretação e de manipulação, conforme veremos ao analisar o caso da ocupação no Iraque.

\section{Reformas econômicas no Iraque ocupado: INDETERMINAÇÃO NA LINGUAGEM DAS NORMAS HUMANITÁRIAS?}

Para considerarmos o limite das medidas que potências ocupantes podem adotar nos territórios ocupados, passaremos a analisar o caso da ocupação liderada pelos Estados Unidos no Iraque. Em específico e dentro dos parâmetros da Regulação 43, buscaremos saber se: (i) as transformações econômicas promovidas pela potência ocupante são voltadas para a restauração e asseguração da ordem e da vida públicas no Iraque; e (ii) se houve um impedimento absoluto para se manter a legislação doméstica.

Cerca de dois meses após o início da guerra liderada por George W. Bush, o Iraque foi ocupado militarmente pelos Estados Unidos e seus aliados. O Conselho de Segurança, depois de ser informado pelos EUA e pelo Reino Unido da invasão, ${ }^{32}$ emitiu a Res. 1483, na qual o status dos dois países como "potências ocupantes" foi reconhecido. ${ }^{33}$ A ocupação militar durou cerca de 14 meses: de meados de maio de 2003 a junho de $2004 .{ }^{34} \mathrm{Na}$ mesma Resolução, o Conselho expressa a obrigação das partes envolvidas de respeitar as Regulações da Haia de 1907 e as Convenções de Genebra de 1949,,35 o que de-

32 É importante ressaltar que, nesse sentido, não há vinculação entre a legalidade da guerra em si (jus ad bellum) com o direito aplicável durante as hostilidades e a ocupação (jus in bello), i.e., mesmo que a guerra seja ilegal, o direito internacional humanitário se aplica durante as hostilidades e/ ou durante a ocupação.

33 "Noting the letter of 8 May 2003 from the Permanent Representatives of the United States of America and the United Kingdom of Great Britain and Northern Ireland to the President of the Security Council (S/2003/538) and recognizing the specific authorities, responsibilities, and obligations under applicable international law of these states as occupying powers under unified command (the "Authority")" ORGANIZAÇÃO DAS NAÇÕES UNIDAS. Conselho de Segurança, Resolução 1483. 22 de maio de 2003. Preâmbulo. Disponível em: <www.un.org>. Acesso em: 14 de set. 2011.

34 A Resolução 1546 do Conselho de Segurança termina oficialmente com a ocupação em 30 de junho de 2004.

35 "Calls upon all concerned to comply fully with their obligations under international law including in particular the Geneva Conventions of 1949 and monstra a aplicabilidade das normas de direito internacional humanitário relativas à ocupação militar iraquiana.

Durante a ocupação, a entidade responsável pela administração do Iraque foi a Coalition Provisional Authority (doravante "CPA"). Sob o comando do diplomata estadunidense Paul Bremer, a CPA emitiu mais de cem ordens e regulações, que abrangiam questões jurídicas, políticas e econômicas. As ordens com conteúdo econômico aparecem desde o começo da ocupação. Inicialmente se referiam a questões de reparos e de revitalização macroeconômica, com temas que variavam do comércio aos tributos. Já na Ordem 39, há expressamente o intento de criar no Iraque uma economia de mercado. $\mathrm{O}$ objetivo declarado passa a ser o de transformar uma economia não transparente centralmente planejada numa economia de mercado, ${ }^{36}$ intenção reiterada nas ordens subsequentes.

A Ordem 39 diz respeito especificamente a investimentos estrangeiros. A Constituição Interina do Iraque de 1990 proibia no seu art. 18 que estrangeiros tivessem propriedade privada no país, a não ser em condições a serem explicitadas em leis posteriores. ${ }^{37}$ Pela "Lei de Empresas" de 1997, ${ }^{38}$ somente iraquianos poderiam estabelecer empresas ou ser sócios de empresas no Iraque. Essa mesma lei conferiu status idêntico a outros nacionais árabes, dentro da diretriz de integração árabe do partido Ba'ath. As regras sobre investimentos como a "Lei de Investimentos Árabes" de 1988 e a posterior Emenda de $2002,{ }^{39}$ também estenderam a outros nacionais árabes privilégios garantidos apenas a empresários iraquianos. Tais privilégios foram extintos com a Ordem 39 da CPA, sobre investimento estrangeiro, que revogou toda a legislação iraquiana anterior (seção 3,

the Hague Regulations of 1907' ORGANIZAÇÃO DAS NAÇÕES UNIDAS. Conselho de Segurança, Resolução 1483. 22 de maio de 2003. Disponível em: <www.un.org>. Acesso em: 14 de set. 2011. Parágrafo $5^{\circ}$.

36 "a non-transparent centrally planned economy to a market economy" , COALITION PROVISIONAL AUTHORITY. Ordem 39, 19 de setembro de 2003, Preâmbulo. Disponível em:< http://www.iraqcoalition.org/>. Acesso em: 11 fev. 2012.

37 "Art. 18. Immobile ownership is probibited for non-Iraqi, except otherwise mentioned by a law." IRAQUE, Constituição Interina do Iraque, 1990. Disponível em: < http://www.servat.unibe.ch/icl/iz00000_.html>. Acesso em: 12 fev. 2012.

38 ESTADOS UNIDOS, Department of Commerce. Overview of Commercial Law in Iraq, 2003, p. 17, Disponível em: <www.aschq. army.mil/gc/files/Iraqi_Comm_Law.pdf>. Acesso em: 12 .fev. 2012.

39 ESTADOS UNIDOS. Department of Commerce. Overview of Commercial Law in Iraq, 2003. Disponível em: <www.aschq.army.mil/ gc/files/Iraqi_Comm_Law.pdf>. Acesso em: 12 .fev. 2012. 
$\left.\$ 1^{\circ}\right),{ }^{40}$ acabou com o tratamento preferencial aos nacionais árabes (seção $\left.4, \$ 1^{\circ}\right)^{41}$ e não limitou o montante da participação de capital estrangeiro (seção $4, \mathbb{\$} 2^{\circ}$ ). ${ }^{42}$

Em suma, a Ordem 39, promulgada pela potência ocupante, iniciou uma brusca alteração no modelo de política econômica no Iraque passando de uma economia centralizada, dita socialista, para uma economia liberal (ou neoliberal, como preferem alguns). Os demais atos legislativos, juntamente com as políticas executivas (ambas centralizadas na CPA) levaram a cabo uma política de ampla liberalização econômica nas áreas tributária, bancária, financeira e comercial, dentre outras.

A questão que se coloca é se as reformas econômicas pela CPA, no Iraque, estariam em conformidade com as normas de direito internacional humanitário. Uma análise técnica dessa situação nos remeteria à Regulação 43 das Regulações da Haia de 1907. Conforme descrevemos, há duas obrigações nesse dispositivo que devem ser lidas concomitantemente: “(i) restaurar e assegurar a ordem e a vida públicas (na medida do possível), (ii) respeitar as leis vigentes (salvo impedimento absoluto)".

Em relação à primeira obrigação, primeiro devemos nos perguntar se as reformas econômicas podem ser entendidas dentro da esfera de ordem e vida públicas. A partir do texto autêntico em francês e dos travaux, principalmente do sentido de "vida pública", fica claro que sim. A potência ocupante deve se preocupar com as questões econômicas do território ocupado, mesmo que essa obrigação não seja categórica, e sim "na medida do possível".Ainda em relação à primeira obrigação, devemos investigar o significado dos verbos "restaurar" e "assegurar", em especial do primeiro, visto o foco do nosso estudo. O ponto de partida da controvérsia re-

40 "Section 3 - Relation to Existing Iraqi Law. 1) This Order replaces all existing foreign investment law." COALITION PROVISIONAL AUTHORITY. Ordem 39, 19 de setembro de 2003. Disponível em: http://www.iraqcoalition.org>. Acesso em: 11 de fev. 2012.

41 "Section 4 - Treatment of Foreign Investors. 1) A foreign investor shall be entitled to make foreign investments in Iraq on terms no less favorable than those applicable to an Iraqi investor, unless otherwise provided herein." COALITION PROVISIONAL AUTHORITY. Ordem 39, 19 de setembro de 2003. Disponível em: http:/ / www.iraqcoalition.org > . Acesso em: 11 de fev. 2012.

42 "Section 4 - Treatment of Foreign Investors. 2) The amount of foreign participation in newly formed or existing business entities in Iraq shall not be limited, unless otherwise expressly provided herein." COALITION PROVISIONAL AUTHORITY. Ordem 39, 19 de setembro de 2003. Disponível em: http://www.iraqcoalition.org>. Acesso em: 11 de fev. 2012. side na questão se "restaurar" significa voltar ao status quo ante bellum, ou seja, restabelecer a situação anterior ao conflito armado. Essa parece ser a opinião de certos comentadores, como Von Glahn. Para ele, restaurar tem o sentido de restabelecer algo que existia anteriormente, donde alterar os aspectos centrais da organização econômica contrariamente às normas do regime anterior excederia a competência legal do art. $43,{ }^{43}$ i.e., a potência ocupante deve apenas restabelecer as diretrizes econômicas anteriormente em vigor e não realizar profundas alterações nas políticas econômicas no território ocupado. De fato, essa interpretação é reforçada ao lermos a segunda obrigação, de respeitar as leis em vigor, em conjunto com a primeira. Deve-se intentar a restauração da ordem e da vida públicas respeitando o quadro jurídico anteriormente construído que, por sua vez, refletia as opções políticas da organização da vida pública. O problema reside na exceção da segunda obrigação: "salvo impedimento absoluto". Como exposto, essa expressão pode ser entendida como "necessidade absoluta". Assim, apenas em casos de necessidade absoluta, a potência ocupante não precisa respeitar as leis vigentes para adotar medidas que visem restaurar e assegurar a ordem e a vida públicas. Essa situação de exceção reduz o questionamento da seguinte forma: havia uma necessidade absoluta de se promoverem reformas econômicas liberais na economia iraquiana a fim de restaurar a ordem e a vida públicas?

Aqueles que respondem afirmativamente a essa questão podem ressaltar que medidas de política econômica seriam indispensáveis para serem atendidos os interesses imediatos da população civil. Situações em que a economia passa por uma recessão ou estagnação graças ao próprio conflito armado podem exigir a adoção de políticas econômicas mais incisivas. Para Benvenisti, por exemplo, um retorno econômico ao status quo ante bellum pode significar a estagnação econômica no território ocupado, ${ }^{44}$ o que obviamente não estaria dentro dos interesses da população civil do território ocupado. De acordo com tal interpretação, a Regulação 43 não obriga a potência ocupante a congelar o status quo caso este tivesse efeitos negativos sobre a economia e sobre a população.

43 von Glahn, Gerhard. Taxation under Belligerent Occupation. In: Playfair, Emma (Ed.) International Law and the Administration of Occupied Territories: Two decades of Israeli Occupation of the West Bank and Gaza Strip. Oxford: Clarendon, 1992. p. 353.

44 BENVENISTI, Eyal. The International Law of Occupation. 2. ed., Princeton: Princeton University Press, 2004. p. 11. 
Os que não concordam com tais argumentos podem rebater que, de fato, a estagnação econômica no território ocupado não contribui para a restauração da ordem e da vida públicas; todavia, estagnação econômica (ou a completa alteração do modelo econômico) parece ter mais sentido em ocupações mais longas, como é a situação nos territórios palestinos. O próprio Benvenisti exemplifica sua argumentação com base em ocupações prolongadas e usa a mencionada ocupação israelense. ${ }^{45}$ É difícil argumentar que uma ocupação de 14 meses como a promovida pelos Estados Unidos e seus aliados no Iraque justifique a adoção de medidas que alteram profundamente o modelo econômico do país. A Regulação 43 não parece permitir alterações profundas e de longo prazo, com objetivos que não sejam respostas pontuais e temporárias.

De qualquer forma, essas duas linhas de argumentação, apresentadas de forma simplista e não exaustiva, nos são úteis apenas para demonstrar a incerteza que caracterizaria nossa resposta frente à pergunta formulada. Ponderar sobre a necessidade absoluta de realizar reformas econômicas exigiria adentrar nos melindres do debate econômico e enfrentar questões como o significado de "estagnação" e de "crise", quais são os problemas econômicos principais a serem resolvidos e quais os melhores indicadores para medi-los, como relevar questões econômicas de curto, de médio e de longo prazos, etc. Afinal, se nos perguntamos se há necessidade absoluta de reformas econômicas, devemos analisar a essência de tal necessidade, sua natureza, seu tamanho e suas áreas econômicas mais afetadas, dentre outros elementos.

O passo seguinte, mais complicado ainda, é sobre o modelo mais adequado para enfrentar tais problemas econômicos. O politizado debate sobre linhas de pensamento econômico, entre liberais, desenvolvimentistas, nacionalistas, socialistas e outros, é por demais longevo e impossibilita uma resposta consensual. Da mesma forma que não há qualquer indício nos textos de direito internacional humanitário que permita a restauração da ordem e da vida públicas de acordo com as preferências de política econômica das potências ocupantes, não há norma escrita ou prática internacional uniforme no sentido de como a potência ocupante deve proceder. Não há um procedimento específico que normatiza a con-

45 BENVENISTI, Eyal. The International Law of Occupation. 2. ed., Princeton: Princeton University Press, 2004. p. 11. duta da potência ocupante em relação a reformas econômicas (assim como em outros assuntos). $\mathrm{Na}$ prática, levar em conta os interesses da população civil pode se revelar uma questão complexa, visto que quem exerce os poderes públicos é a potência ocupante e os canais de participação popular no governo são mínimos ou ainda inexistentes. Argumentar que os limites à potência ocupante são estabelecidos nas próprias normas de direito internacional humanitário, tampouco faz o debate avançar muito no que diz respeito aos detalhes de como a potência ocupante deve proceder em situações de reformas econômicas no país ocupado. Em suma, as indeterminações das normas de direito internacional humanitário relativas à ocupação militar de territórios impossibilitam uma resposta mais ou menos certeira que evite o abuso promovido por aqueles que têm mais poder.

\section{Considerações finais}

O discurso em defesa das normas de direito internacional humanitário está arquitetado na premissa de que é possível reduzir o sofrimento humano em conflitos armados. Limitar os meios de combate e tentar reduzir ao mínimo a destruição, assim como as causalidades, faz parte dos objetivos declarados deste antigo corpo juris do direito internacional. Além de regular as hostilidades em conflitos armados per se, as normas humanitárias também são aplicáveis em situações em que um Estado ocupa militarmente o território de outro após um conflito armado. Nesses casos, as normas humanitárias se pautam pela tentativa de regular essa situação, por meio de um discurso de neutralidade entre as partes conflitantes e de proteção da população civil.

Apesar da pretensão de não se relacionar com a legalidade do ato da ocupação militar em si (jus ad bellum), o quadro de normas humanitárias aplicáveis durante a ocupação (jus in bello) regula a legalidade das ações da potência ocupante no território ocupado. $\mathrm{O}$ fato do Conselho de Segurança da ONU não ter autorizado a invasão militar liderada pelos estadunidenses no Iraque, em julho de 2003, não o impediu de reconhecer a ocupação militar no território iraquiano e o dever de ele ser administrado segundo as normas humanitárias. Quando se reconhece um território como ocupado - e para isso basta que a potência ocupante tenha controle efetivo sobre o território -, reconhece-se, outrossim, a competência da potência ocupante para administrá-lo. Suas ações 
passam a ser reguladas pelas normas humanitárias que, ao mesmo tempo, impõem deveres e concedem direitos aos ocupantes.

O cerne das normas humanitárias relativas à ocupação militar é a Regulação 43 das Regulações da Haia de 1907. Em poucas linhas, esse dispositivo contém a essência da administração de territórios ocupados. Redigido há mais de um século por representantes de vários Estados, inclusive de algumas potências com possessões coloniais e políticas imperialistas, esse dispositivo é oriundo de um tempo em que a aquisição de territórios por meio de guerras não era incomum. Ademais, foi escrito no contexto do começo do século XX, em um momento de forte influência do pensamento positivista no direito internacional, que tem como uma dentre outras consequências, a ideia de que o que não é proibido é permitido. ${ }^{46}$ Dessa forma, a Regulação 43 não estabelece um quadro detalhado de como a potência ocupante deve proceder e quais os limites para sua atuação; e, ao não fazê-lo, abre grande espaço de manobra para a potência ocupante. É por meio da indeterminação dessa norma que se cria espaço para abusos por parte da potência ocupante.

A indeterminação das normas humanitárias relativas à ocupação territorial é facilmente observada no caso do Iraque. A administração territorial comandada pelos EUA fez uma série de reformas econômicas que alteraram radicalmente o modelo econômico iraquiano até então vigente: segundo sua interpretação, ${ }^{47}$ havia uma necessidade de alteração na estrutura econômica iraquiana, e a preferência estadunidense, que tinha competência na administração territorial, era pelo modelo liberal. Mesmo a partir de uma leitura não tão estrita das normas humanitárias ou ainda interpretando as Regulações de 1907 à luz dos instrumentos mais recentes do direito internacional humanitário, pouco será encontrado em relação às alterações na economia do território ocupado. Várias questões continuam abertas, o que dá margem para práticas abusivas por parte daqueles que têm em suas mãos amplos poderes para administrar as riquezas e os povos subjugados e quase nenhum limite imposto que cerceie suas escolhas.

46 Ver: Corte Permanente de Justiça Internacional. SS Lotus Case (França v. Turquia). PCIJ Rep., (1927), series A, n.. 10. J. em: 7 set. 1927, p.19-21.

47 Cf., por exemplo: YOO, John. Iraqi Reconstruction and the Law of Occupation. University of California Davis Journal of International Law and Policy. v. 11, n. 7, p. 7-22, 2004.

\section{ReferênCIAs}

BENVENISTI, Eyal. The International Law of Occupation. 2. ed. Princeton: Princeton University Press, 2004.

Coalition Provisional Authority, Ordem 39. 19 de setembro de 2003. Disponível em: <www.iraqcoalition.org>. Acesso em: 11 fev. 2012.

CONVENTION (IV) concernant les lois et coutumes de la guerre sur terre et son Annexe: Règlement concernant les lois et coutumes de la guerre sur terre. A Haia, 18 de outubro de 1907. Disponível em: <http://www. icrc.org/dih.nsf/full/195>. Acesso em: 14 set. 2011.

CORTE INTERNACIONAL DE justiça. Armed Activities on the Territory of the Congo (Democratic Republic of the Congo v. Uganda). Haia: ICJ Reports, 2005. J. em: 19 de dezembro de 2005.

CORTE INTERNACIONAL DE justiça. Legal Consequences of the Construction of a Wall in the Occupied Palestinian Territory: Advisory Opinion. Haia: ICJ Reports 2004.

Corte Permanente de Justiça Internacional. SS Lotus Case (França v. Turquia). PCIJ Rep., (1927), series A, n. 10. J. em: 7 de setembro de 1927.

DINSTEIN, Yoram. Legislation Under Article 43 of the Hague Regulations: Belligerent Occupation and Peacebuilding. Occasional Paper Series, Program on Humanitarian Policy and Conflict Research, Harvard University, n. 1, nov. 2004. p. 6-8. Disponível em: $<$ http:// www.hpcr.org/publications/ops.php>. Acesso em: 11 fev.2012.

DINSTEIN, Yoram. The International Law of Belligerent Occupation. Nova York: Cambridge University Press, 2009.

ESTADOS UNIDOS, Department of Commerce. Overview of Commercial Law in Iraq, 2003, p. 17, Disponível em: <www.aschq.army.mil/gc/files/Iraqi_Comm_Law. pdf>.. Acesso em: 12 fev. 2012.

GREENWOOD, Christopher. The Administration of Occupied Territory in International Law. In: Playfair, Emma (Ed.) International Law and the Administration of Occupied Territories: Two decades of Israeli Occupation of the West Bank and Gaza Strip. Oxford: Clarendon, 1992.

Institut de Droit International. The Laws of War on Land. 
Oxford, 9 de setembro de 1880. Disponível em: <www. icrc.org/ihl.nsf/FULL/140?OpenDocument>. Acesso em: 14 set. 2011.

IRAQUE, Constituição Interina do Iraque, 1990. Disponível em: <www.servat.unibe.ch/icl/iz00000_.html>. Acesso em: 12 fev. 2012.

MILITARY TRIBUNALS IN THE UNITED STATES. United States of America v Wilhelm List et al (Judgment). Case n. 7, J. em: 19 de fevereiro de 1948. XI Trials of War Criminals before the Nürnberg Military Tribunals under Control Council Law, Washington, US GPO, $n$. 10, p. 1243, [1948?].

ORGANIZAÇÃO DAS NAÇÕES UNIDAS. Conselho de Segurança. Resolução 1483, 22 de maio de 2003. Disponível em: <www.un.org>. Acesso em: 14 set. 2011.

Pictet, Jean. Commentary on Geneva Convention IV Relative to the Protection of Civilian Persons in Time of War. Genebra: ICRC, 1958.

RORIZ, João Henrique Ribeiro. O desenvolvimento normativo dos crimes de guerra: das primeiras noções ao Tribunal Penal Internacional. In: VEÇOSO, Fabia Fernandes Carvalho. Direito Internacional em Contexto. São Paulo: Saraiva, 2012.

Sassòli, Marco. Legislation and Maintenance of Public
Order and Civil Life by Occupying Powers. European Journal of International Law, v. 16, n. 4, p. 661-694, 2005.

Schwenk, Edmund H. Legislative Power of the Military Occupant Under Article 43, Hague Regulation. Yale Law Journal, Yale, v. 54, p. 393-416, 1945.

Tribunal Militar Internacional (Nuremberg), Judgment and Sentences, 1946, American Journal of International Law. n. 41, p. 172-333, 1947.

TRIBUNAL PENAL INTERNACIONAL PARA A EX-IUGOSLÁVIA. Prosecutor v. Naletilić \& Martinovic, (IT-98-34-T) "Tuta and Štela", Judgment. J. em : 31 de março de 2003.

TRIBUNAL PENAL INTERNACIONAL. Prosecutor v. Thomas Lubanga Dyilo. Judgment pursuant to Article 74 of the Statute (ICC-01/04-01/06). J. em: 14 de março de 2012.

von Glahn, Gerhard. Taxation under Belligerent Occupation. In: Playfair, Emma (Ed). International Law and the Administration of Occupied Territories: Two decades of Israeli Occupation of the West Bank and Gaza Strip. Oxford: Clarendon, 1992.

YOO, John. Iraqi Reconstruction and the Law of Occupation. University of California Davis Journal of International Law and Policy. v. 11, n. 7, p. 7-22, 2004. 
Para publicar na Revista de Direito Internacional, acesse o endereço eletrônico www.rdi.uniceub.br ou www.brazilianjournal.org.

Observe as normas de publicação, para facilitar e agilizar o trabalho de edição. 